\title{
Cyclopoid copepods as bioindicators of eutrophication in reservoirs: Do patterns hold for large spatial extents?
}

\author{
Gilmar Perbiche-Neves ${ }^{a, *}$, Victor S. Saito ${ }^{b}$, Daniel Previattelli ${ }^{c}$, Carlos E.F. da Rochac ${ }^{c}$, \\ Marcos G. Nogueira ${ }^{\mathrm{d}}$ \\ a Centro de Ciências da Natureza, Universidade Federal de São Carlos, Campus Lagoa do Sino, Buri, SP, Brazil \\ b Programa de Pós-Graduação em Ecologia e Recursos Naturais, Universidade Federal de São Carlos, São Carlos, SP, Brazil \\ c Laboratório de Meiofauna, Universidade de São Paulo, USP, IB, Departamento de Zoologia, São Paulo, SP, Brazil \\ ${ }^{d}$ Universidade Estadual Paulista, UNESP, IB, Departamento de Zoologia, Distrito de Rubião Jr., Botucatu, SP, Brazi
}

\section{A R T I C L E I N F O}

\section{Article history:}

Received 5 October 2015

Received in revised form 14 June 2016

Accepted 15 June 2016

Available online 27 June 2016

\section{Keywords:}

Reservoirs

Water quality

Bioindicators

Zooplankton

Biomonitoring

Large scale assessment

\begin{abstract}
A B S T R A C T
Some species of copepods are sensitive to water quality oscillations from natural or anthropogenic causes. Information on basic ecological attributes such as abundance can be helpful in the context of hydric resources monitoring. Our study analyzed if the abundance of 22 copepod species of the second largest basin of South America was more associated with variables oscillating by natural or anthropic causes, contrasting among oligotrophic, mesotrophic, and eutrophic reservoirs. Our aim was to identify and understand the abundance of species with potential to monitor water quality in large scale assessments. Potential bioindicators would have different abundances in eutrophic, mesotrophic and oligotrophic sites and would not oscillate according to natural characteristics of reservoirs (water temperature, air temperature, and depth). Two species were sensitive to eutrophication and were not related to natural characteristics of reservoirs, that is, they were suitable for biomonitoring the La Plata Basin. Thermocyclops minutus negatively responded to eutrophication, while Acanthocyclops robustus responded positively. Additional exploratory analyses identified that Copepod abundance was related to total phosphorus, chlorophyll-a concentration, water transparency, total suspended matter, and depth. Metacyclops mendocinus, Acanthocyclops robustus, Mesocyclops meridianus, Mesocyclops ogunnus, and Thermocyclops decipiens were abundant in eutrophic reservoirs, and Thermocyclops minutus, and Thermocyclops inversus were associated with higher water transparency, typically oligo/mesotrophic reservoirs. Overall, we found that cyclopoids are highly affected by eutrophication, and species abundance could be used to monitor reservoirs and anticipate potential impacts on water quality in large-scale biomonitoring schemes.
\end{abstract}

(c) 2016 Elsevier Ltd. All rights reserved.

\section{Introduction}

Freshwater copepods constitute a functional link between phytoplankton and bacterioplankton and higher trophic levels, such as fish and invertebrate larvae. Due to this important relationship with all taxonomic groups in aquatic environments, the population abundance of these organisms as well as richness, diversity, and biomass can be viewed as an interesting indicator of the overall ecological condition of the whole water body (Landa et al., 2007; Santos-Wisniewsky and Rocha, 2007; Silva, 2011).

\footnotetext{
* Corresponding author.

E-mail addresses: gilmarpneves@yahoo.com.br (G. Perbiche-Neves), victor.saito@gmail.com (V.S. Saito),dpreviattelli@gmail.com (D. Previattelli), cefrocha@usp.br (C.E.F. da Rocha),nogueira@ibb.unesp.br (M.G. Nogueira).
}

A current challenge in monitoring studies is to separate the natural fluctuation of bioindicator populations from the fluctuation related to anthropic impacts in order to find suitable indicator species. In this sense, interesting bioindicator taxa are those who have any biological or ecological characteristic (i.e., density, body size) strongly influenced by anthropic impacts and weakly influenced by natural fluctuations (Bonada et al., 2006). Certain neotropical copepod species are particularly sensitive to several environmental variables and can potentially serve as indicators of distinct trophic stages (Matsumura-Tundisi and Tundisi, 2003), including artificial lakes near large cities that receive large quantities of sewage, resulting in high values of nutrients and chlorophyll.

Eutrophication is a detrimental process characterized by the enrichment of aquatic systems mainly by nitrogen and phosphorous (Serafim-Júnior et al., 2010). The increased of primary 
productivity caused by nutrient enrichment strongly affects species of zooplankton, macroinvertebrates, and fish and ultimately can affect all those that directly or indirectly make use of the contaminated water from eutrophic reservoirs (Serafim-Júnior et al., 2010). Moreover, eutrophication of reservoirs also has an economic impact on lakefront property values, drinking water prices, and availability and spending on the recovery of endangered species (Dodds et al., 2008). Due to all these potential impacts, it is imperative to develop biomonitoring schemes that enable anticipating the eutrophication of reservoirs.

In general, zooplankton abundance is positively correlated to high values of chlorophyll-a (generally dominated by few species) and nutrients (especially $\mathrm{N}$ and $\mathrm{P}$ ) and negatively to conductivity (sewage) and low dissolved oxygen. Besides these general trends, individual response of each species is less known and would be desirable to simplify biomonitoring schemes by using a smaller number of species with the best response to eutrophication.

Studies have considered only restricted or intermediary spatial scales and have still not focused on relations between copepods and water quality or eutrophication in an entire large river basin. Since generalizations are one of the most desired aims in biomonitoring (Bonada et al., 2006), studies encompassing biological responses along a large environmental gradient could provide information about general bioindicators for this scale. In this sense, here we investigated the La Plata Basin, which is the second largest basin in South America, and it has one of the most highly concentrated human populations in the continent. From a large-scale perspective, the basin is composed by important rivers such as the Parana, Paraguay, and Uruguay rivers and by several reservoirs mainly in the upper part of the basin. Many rivers are almost totally dammed and are severely impacted by large quantities of sewage produced every day by large cities.

The aim of this study was to identify which species of cyclopoid copepods exhibit consistent trends of abundance in reservoirs along an environmental gradient of anthropogenic impact in a large river basin. We applied a combination of statistical filters to select bioindicator species of trophic states of reservoirs using established methods for biomonitoring (Barbour et al., 1996; Hering et al., 2006; Saito et al., 2015). We further explored the relationships between cyclopoids and limnological variables using two different exploratory statistical techniques aiming to understand the specific response of individual species to natural and anthropic variables.

\section{Materials and methods}

\subsection{Study area and sampling design}

Approximately $60 \%$ of the upper Paraná River, which is the main drainage of La Plata Basin, is already dammed for hydropower generation and has only a few free lotic stretches. The opposite situation is found in the middle and lower stretches where reservoirs are almost absent, and an increase in turbidity and suspended matter naturally occurs below the mouths of tributaries. A similar pattern is observed in the Uruguay River, but the difference is that a large reservoir has built up in the middle-lower stretch. Few reservoirs have been constructed in the headwaters of the Paraguay River and none in the main channel.

Some important tributary rivers of the upper Paraná River drain large cities in the headwaters, totaling more than 27 million people (e.g., Curitiba, São Paulo, Campinas), and have along their courses a series of cascade downstream reservoirs that exhibit a longitudinal decrease in nutrients, chlorophyll-a, and eutrophication along the cascade (Barbosa et al., 1999; Silva et al., 2005). However, this phenomenon does not occur in parallel in large rivers without the influence of large cities in the headwaters, where nutrients and eutrophication sources have local influence, for example, in arms and tributary mouths (Nogueira et al., 2008).

In this study, we sampled the largest area of the La Plata River Basin possible, covering approximately $70 \%$ of the basin (for a total of 3,100,000 $\mathrm{km}^{2}$ ); the basin extends to Argentina, Brazil, Bolivia, Paraguay, and Uruguay. Triplicate samples were obtained twice from 30 sites in the basin, during summer and winter of 2010. Fifteen reservoirs were selected (samples from the lacustrine zones adjacent to the dams and from riverine zones in the upstream [tail zone]) (Fig. 1). All of the sampled reservoirs exhibited a water retention time greater than 15 days, which is considered the limiting lower period for the development of certain regional copepod species (Rietzler et al., 2002).

\subsection{Environmental variables}

Thirteen environmental variables were measured in conjunction with zooplankton sampling. Several variables were measured in situ: water temperature, $\mathrm{pH}$, electrical conductivity, and dissolved oxygen were quantified with a multiparameter Eureka Manta-2 probe; depth was measured with a SpeedTech probe; water transparency $(\mathrm{m})$ was determined with a Secchi disk; and air temperature was measured with a mercury thermometer. Water samples were collected with a Van Dorn bottle for subsequent laboratory analyses of total nutrient concentrations (phosphorus and nitrogen), suspended matter (total, inorganic, and organic), and chlorophyll-a. In deeper stations (>30 m), water samples were obtained from four to six depths according the local depth but always including at least the surface, middle, and end of the euphotic zone and near the bottom. For example, in reservoirs with $40 \mathrm{~m}$ depth, we took four samples, and in $150 \mathrm{~m}$ reservoirs, we took 6 samples. Shallow sites $(<15 \mathrm{~m})$ were sampled at three depths, at surface, middle and close to the bottom. The mean depth of sampling sites is available in Supplementary file 1. Mean values among depths were calculated for subsequent analyses.

Using the values of total phosphorus, chlorophyll-a, and water transparency, we calculated a classic trophic state index for lakes (Carlson, 1977) to characterize the trophic level of the sampled sites.

\subsection{Zooplankton sampling}

Zooplankton triplicate samples were obtained with vertical hauls in the water column (from just above to the bottom to the surface) at each sampling station. The water volume was determined with the cylinder volume formula ( $=\pi$.raius of the plankton net height). In deeper stations, the vertical hauls reach an extension of $40 \mathrm{~m}$. The minimum and maximum sampled volume used was $400 \mathrm{~L}$ and $1884 \mathrm{~L}$, respectively. Conical plankton nets of $68 \mu \mathrm{m}$ mesh size modified with an anti-reflux bulkhead were used, and the samples were fixed with $4 \%$ formalin solution.

Copepods were identified under optical microscopy (Zeiss Standard 20 and 25) with specialized references (as cited in Perbiche-Neves et al., 2014). Adult males and females of all species were identified. Quantitative analyses were conducted in subsamples obtained by a Stempel sampler, considering at least 500 individuals per sample or the entire sample in case of low abundance and using acrylic chambers under a stereomicroscope. Abundance was expressed in individuals per cubic meter $\left(\right.$ ind $\mathrm{m}^{-3}$ ).

\subsection{Data analysis}

\subsubsection{Selecting copepod bioindicators}

We used a combination of statistical filters to select bioindicator species of trophic states of reservoirs for large-scale biomonitoring programs. The use of these filters was based on established meth- 


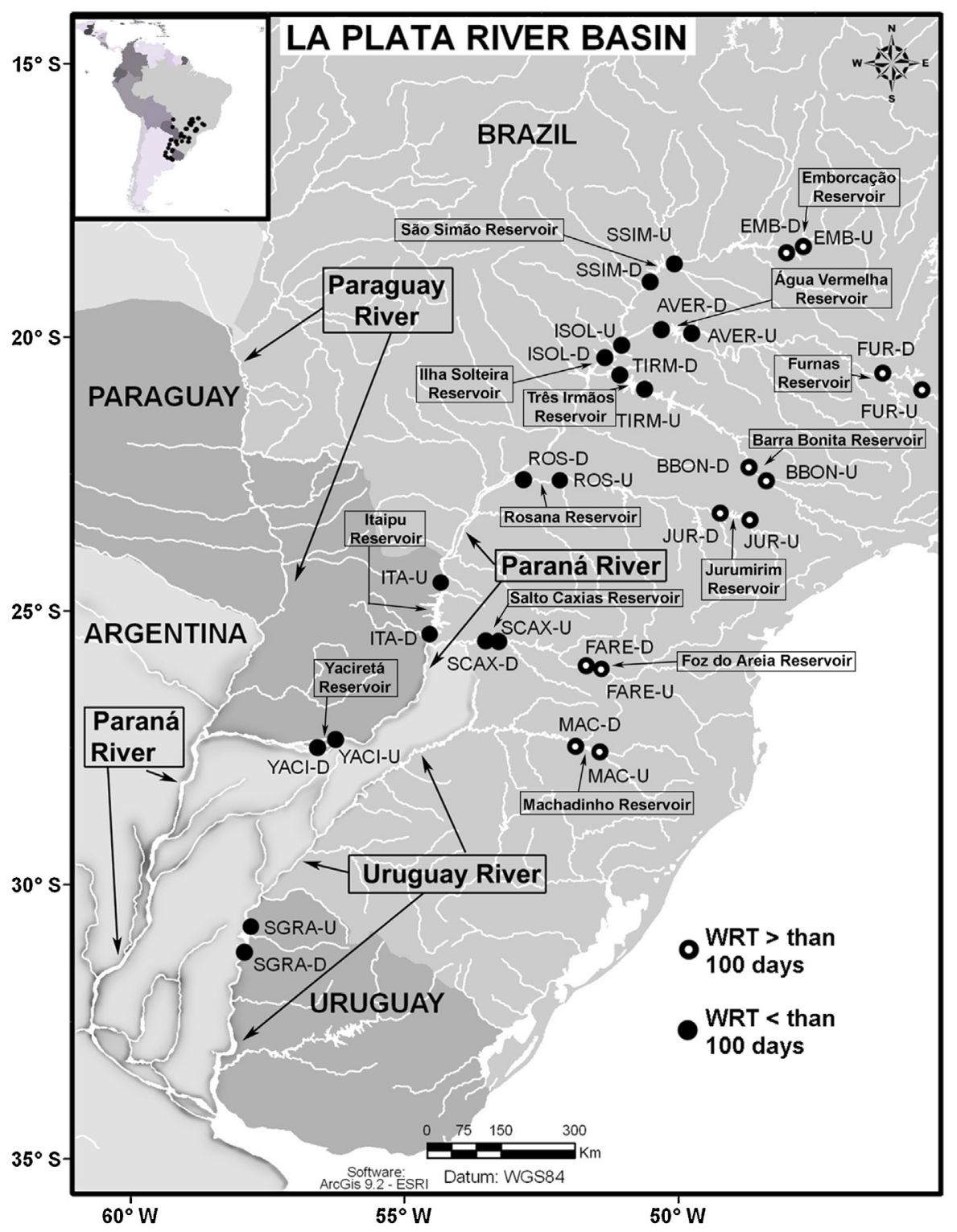

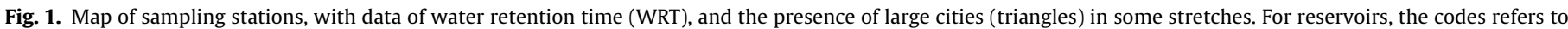
the first three letters of the name of reservoir, and after hyphen, the letter "U" means "upstream" and the letter "D" means "dam zone".

ods for selecting metrics for biomonitoring (Barbour et al., 1996; Hering et al., 2006; Saito et al., 2015). For these analyses, we tested separated males and females of species due to the potential that gender plays on the response to environmental impacts (Burger, 2007).

\subsubsection{First filter-simper analysis}

First, we used a Simper analysis to identify which species mostly contributed to the dissimilarity among groups of reservoirs with different trophic states. Simper analysis indicates the average contribution of individual species to the average Bray-Curtis dissimilarity among sites from different groups (Clarke, 1993). We used a threshold of $70 \%$ of ordered accumulated contribution to select species that have potential to distinguish trophic states. Species that do not contribute to this amount of accumulated contribution vary little among trophic states and are not suitable for biomonitoring purposes.

\subsubsection{Second filter-sensitivity analysis}

Species selected by the Simper analysis were then subjected to box-and-whiskers-plot analysis coupled with one-way ANOVAs to identify which species have different abundances in the three trophic states (Barbour et al., 1996; Saito et al., 2015). Species with indicator potential were those with significant differences in all pairwise comparisons.

\subsubsection{Third filter-correlation to natural variables}

The third filter tested the correlation among selected indicator species and the natural variables air temperature, water temperature, and reservoir depth. The aim of this filter is to identify species that vary strongly due to both natural and anthropic causes. Species with Spearman $r>0.8$ would be inappropriate for biomonitoring due to the possible confounding effects that natural and anthropic impacts could have on species abundance (Hering et al., 2006).

\subsubsection{Exploratory analyses}

Specific relationships among copepod abundance and 15 variables (water temperature, $\mathrm{pH}$, electrical conductivity, dissolved 
oxygen, depth, water transparency, air temperature, total phosphorus, total nitrogen, suspended matter [total, inorganic and organic], and chlorophyll) were further investigated using exploratory analysis (redundancy analysis - RDA) and regressions (partial least squares - PLS) using log-transformed data. RDA is a form of constrained ordination that examines how much of the variation in one set of variables explains the variation in another set of variables and is the multivariate analog of simple linear regression. The RDA was performed as described by Oksanen et al. (2014) with the Vegan package version 2.2. After the variance determination to be inertial, all the species abundance values were standardized using correlation coefficients, and inertial correlations were obtained. This was done to prevent disproportionate effects of highly abundant taxa (even though they are log transformed).

PLS regressions were used to filter which limnological variables were related to copepod abundance. As dependent variables representative of copepods for PLS regressions, we used the first component of site score (weighted sums of species scores) of RDA with high variance explicability and also the log-transformed abundance of each more abundant species. PLS shows an advantage with multiple linear regressions because it circumvents the problem of the collinearity of limnological variables, for example, nutrient concentration, chlorophyll-a, transparency, turbidity, total suspended matter, etc. PLS decomposes variables into orthogonal scores and loadings (Mevik and Wehrens, 2007). We used the "pls" package version 2.4 for R (Mevik et al., 2013), and the "classical orthogonal score" algorithm fit method was employed. To select more important variables acting on individual dependent variables, we calculated Variable Importance in the Projection (VIP), further we plotted the regression coefficients of first and second most important components.

All statistical analyses were performed using $\mathrm{R}$ software version 3.3.0 (R Development Core Team, 2016).

\section{Results}

\subsection{Environmental variables}

Among the 30 sampling sites along the basin, the majority were classified as oligotrophic (66\%), followed by mesotrophic (22\%), and few sampling sites (12\%) were classified as eutrophic (Table 1 ). High mean values of chlorophyll, total phosphorus, and electrical conductivity occurred in eutrophic reservoirs, which was opposite with the high transparency at oligotrophic sites. It is important to highlight that the Carlson index is considered to be a sub-optimal estimate for tropical areas; thus, some oligotrophic sites could be considered as mesotrophic using different trophic classifications. A list with the mean values of all environmental variables is present in the Supplementary file 1.

\subsection{Zooplankton}

We identified 22 species in reservoirs from the La Plata river basin. Details regarding the assemblages' diversity and the complete taxonomical list, including other orders of Copepoda as well, can be found in Perbiche-Neves et al. (2014) and in Neves (2011). A matrix of more abundant species is available in Supplementary files 2.

Species which contributed to $70 \%$ of the dissimilarity (BrayCurtis) among groups of reservoirs were considered important to distinguish trophic states. Following this threshold, we found that T. decipiens (female) (23\%), T. minutus (f) (13\%), A. robustus (male) (8\%), T. decipiens (m) (7\%), and A. robustus (f) (6\%) were important species to distinguish eutrophic from mesotrophic reservoirs. Thermocyclops minutus (f) (31\%), T. decipiens (f) (12\%), T. inversus (f) ( $8 \%)$, and T. minutus (m) (6\%) were the most important species to distinguish eutrophic from oligotrophic reservoirs, and T. minutus (f)

Table 1

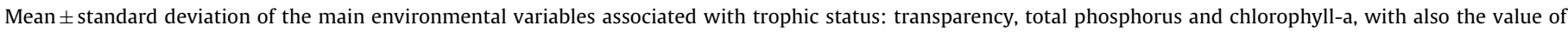
trophic state index (T.S.I.) and the trophic level found. Limits of T.S.I.: Oligotrophic < 44; Mesotrophic between 44-54; Eutrophic > 54.

\begin{tabular}{|c|c|c|c|c|c|}
\hline Sampling site & Transparency (m) & Total Phosphorus $\left(\mu \mathrm{gL}^{-1}\right)$ & Chlorophyll-a ( $\left.\mathrm{mg} \mathrm{L}^{-1}\right)$ & T.S.I. value & Level \\
\hline EMB-U & $2.925 \pm 1.17$ & $8.19 \pm 2.59$ & $1.16 \pm 0.59$ & 38.25 & Oligo \\
\hline EMB-D & $5.6 \pm 0.57$ & $5.06 \pm 0.60$ & $0.70 \pm 0.23$ & 28.78 & Oligo \\
\hline SSIM-SSIM-UM & $3.25 \pm 1.63$ & $10.5 \pm 0.17$ & $1.17 \pm 0.73$ & 38.89 & Oligo \\
\hline SSIM-SSIM-DB & $4.75 \pm 3.89$ & $14.61 \pm 0.88$ & $1.82 \pm 1.76$ & 43.48 & Oligo/Meso \\
\hline FUR-FUR-UM & $1.9 \pm 1.70$ & $8.57 \pm 0.97$ & $2.47 \pm 0.24$ & 42.11 & Oligo \\
\hline FUR-BFUR-D & $4.67 \pm 0.95$ & $7.36 \pm 2.72$ & $0.64 \pm 0.54$ & 30.29 & Oligo \\
\hline AVER-MAVER-U & $2.8 \pm 1.70$ & $9.39 \pm 2.23$ & $3.48 \pm 3.22$ & 44.74 & Meso \\
\hline AVER-BAVER-D & $3.9 \pm 2.40$ & $8.80 \pm 0.67$ & $3.21 \pm 3.04$ & 42.57 & Oligo \\
\hline BBON-MBBON-U & $1.37 \pm 0.25$ & $145.23 \pm 85.08$ & $17.66 \pm 19.21$ & 55.27 & Eutro \\
\hline BBON-BBBON-D & $1.17 \pm 0.60$ & $60.84 \pm 8.77$ & $5.70 \pm 5.11$ & 53.30 & Eutro \\
\hline TIRM-MTIRM-U & $3.82 \pm 1.66$ & $15.66 \pm 3.13$ & $2.80 \pm 0.31$ & 43.52 & Oligo/Meso \\
\hline TIRM-BTIRM-D & $4.45 \pm 2.33$ & $11.02 \pm 1.90$ & $2.62 \pm 1.03$ & 41.64 & Oligo \\
\hline JUR-MJUR-U & $1.65 \pm 1.06$ & $11.41 \pm 0.38$ & $1.62 \pm 0.78$ & 42.59 & Oligo \\
\hline JUR-BJUR-D & $1.75 \pm 0.92$ & $12.04 \pm 0.25$ & $1.34 \pm 0.22$ & 41.05 & Oligo \\
\hline ROS-MROS-U & $1 \pm 0.85$ & $21.55 \pm 1.13$ & $0.83 \pm 0.61$ & 46.76 & Meso \\
\hline ROS-BROS-D & $1.25 \pm 0.78$ & $22.74 \pm 3.12$ & $2.23 \pm 2.09$ & 50.11 & Meso \\
\hline FARE-MFARE-U & $1.45 \pm 0.21$ & $11.06 \pm 1.73$ & $1.16 \pm 0.75$ & 40.50 & Oligo \\
\hline FARE-BFARE-D & $1.5 \pm 0.14$ & $11.02 \pm 0.95$ & $1.00 \pm 0.35$ & 38.97 & Oligo \\
\hline SCAX-MSCAX-U & $1.22 \pm 1.10$ & $22.13 \pm 0.89$ & $2.06 \pm 1.84$ & 50.13 & Meso \\
\hline SCAX-BSCAX-D & $1.65 \pm 0.49$ & $17.39 \pm 4.57$ & $0.83 \pm 0.16$ & 38.32 & Oligo \\
\hline ISOL-MISOL-U & $4.47 \pm 4.63$ & $25.95 \pm 4.07$ & $3.40 \pm 2.39$ & 50.65 & Meso \\
\hline ISOL-BISOL-D & $4.35 \pm 3.04$ & $16.35 \pm 2.27$ & $2.05 \pm 0.67$ & 42.22 & Oligo \\
\hline ITA-MITA-U & $2 \pm 0.71$ & $14.89 \pm 2.89$ & $0.92 \pm 0.86$ & 39.07 & Oligo \\
\hline ITA-BITA-D & $2.2 \pm 1.13$ & $13.2 \pm 1.00$ & $0.91 \pm 0.57$ & 37.76 & Oligo \\
\hline YACI-MYACI-U & $1.62 \pm 0.39$ & $11.85 \pm 4.11$ & $0.77 \pm 0.38$ & 40.09 & Oligo \\
\hline YACI-BYACI-D & $1.9 \pm 0.28$ & $10.19 \pm 0.90$ & $1.08 \pm 0.64$ & 38.58 & Oligo \\
\hline MAC-MMAC-U & $1.72 \pm 0.18$ & $13.10 \pm 7.06$ & $1.76 \pm 0.08$ & 42.32 & Oligo \\
\hline MAC-BMAC-D & $2 \pm 0.42$ & $15.99 \pm 1.14$ & $1.71 \pm 0.76$ & 42.38 & Oligo \\
\hline SGRA-MSGRA-U & $0.72 \pm 0.25$ & $31.45 \pm 6.44$ & $3.26 \pm 1.92$ & 53.79 & Meso/Eutro \\
\hline SGRA-BSGRA-D & $0.72 \pm 0.25$ & $30.84 \pm 17.61$ & $2.82 \pm 2.17$ & 54.62 & Eutro \\
\hline
\end{tabular}


(47\%) and T. inversus (f) (13\%) were the most important species to distinguish among oligotrophic and mesotrophic reservoirs. A complete list of the contributions of each species can be found in the Supplementary files 3.

Following the results of the Simper analysis, which identified species that mostly contributed to the dissimilarity among trophic states, we used box-and-whiskers-plots and one-way ANOVAs to identify which species could statistically distinguish the three trophic states. Thermocyclops minutus (f) and (m) and A. robustus (f) were the only two species that could distinguish between the three trophic states. Thermocyclops inversus (f) and T. decipiens (m) separated mesotrophic from oligotrophic reservoirs only, and A. robustus ( $\mathrm{m}$ ) distinguished only oligotrophic from mesotrophic reservoirs (Fig. 2).

The last filter tested the correlation among species selected by the box-and-whiskers-plots and three natural variables. As expected, males and females of T. minutus were correlated, but the value was below the biomonitoring threshold of 0.75 (Hering et al., 2006). Thermocyclops minutus, both males and females, were weakly related to A. robustus. Neither T. minutus nor A. robustus were correlated to air temperature, water temperature, or reservoir depth, indicating that variation in these species abundances was mainly related to the trophic states of the reservoirs (Table 2).
A redundancy analysis explained $64 \%$ of the data variance and suggested two groups of variables and copepod species (Fig. 3). One group contained species formed by A. robustus, M. mendocinus, $M$. meridianus, $T$. decipiens, and M. ogunnus associated with total nitrogen and phosphorus, chlorophyll-a, and electrical conductivity, indicating more productive and impacted reservoirs (especially Barra Bonita Reservoir). Among the Thermocyclops genera, T. decipiens was associated with eutrophic conditions, and T. minutus and $T$. inversus were associated with water transparency from oligo/mesotrophic reservoirs.

The PLS regressions filtered the effects of limnological variables on copepods, and some trends emerged. We found positive effects of total phosphorus, chlorophyll-a, water transparency, and mean depth that delineated differences between eutrophic and non-eutrophic environments. We also found a negative effect of total suspended matter, contrasting with water transparency and mean depth (Table 3 ). The first axis of RDA scores used as a dependent variable showed the high variance explained (61\%) in the two first components of PLS; this suggests that there are positive effects on copepods abundance from total phosphorus, total suspended matter, and mean depth and negative effects from chlorophyll-a and water transparency. Results of Variable Importance in the Projection reinforced the results of RDA, showing higher importance of total phosphorus and total nitrogen for most of species (see Sup-
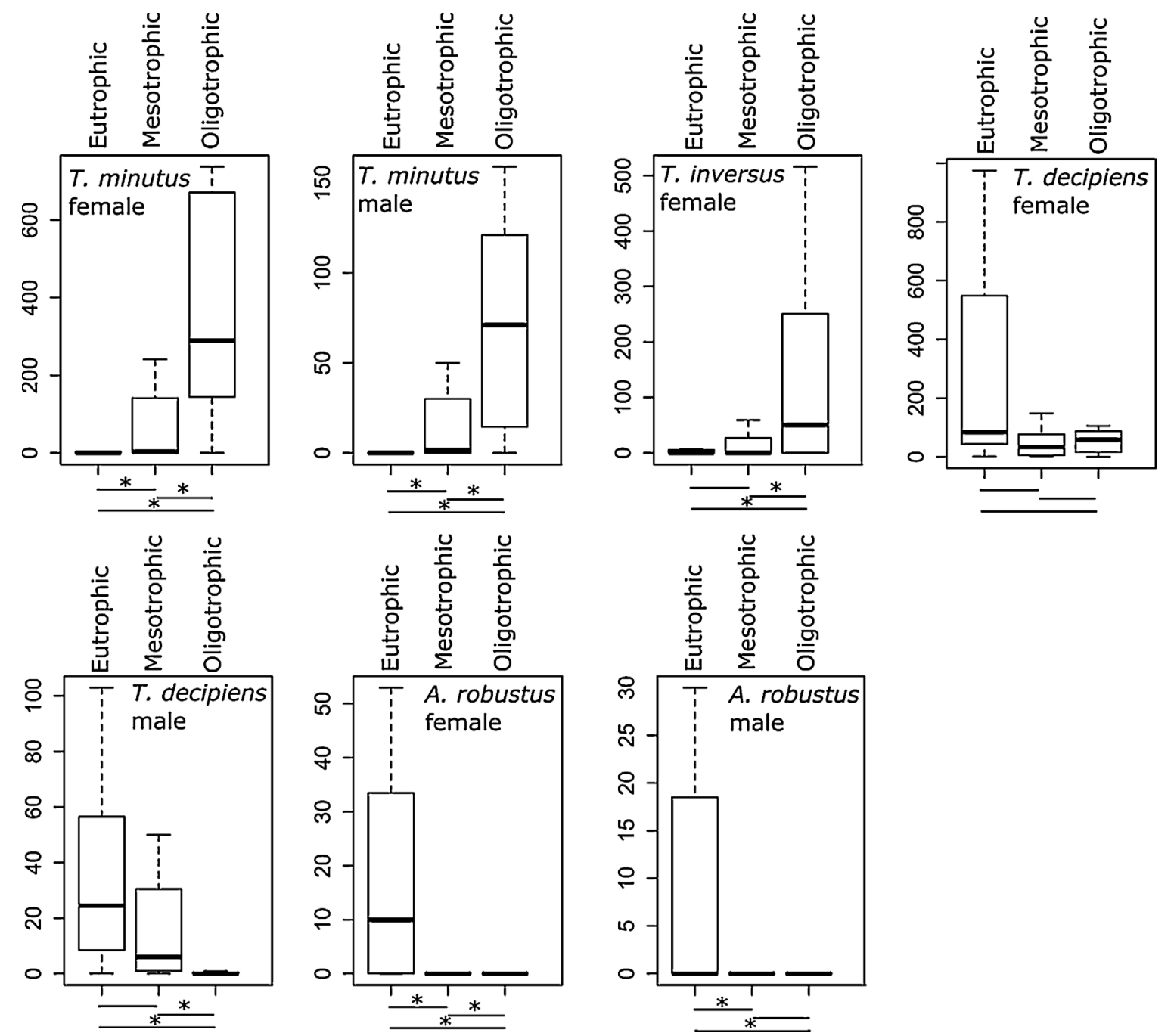

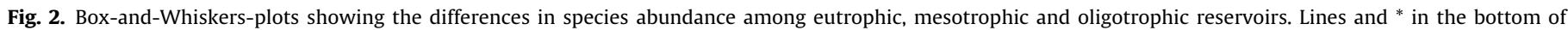

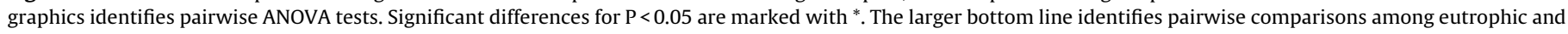
oligotrophic reservoirs. 
Table 2

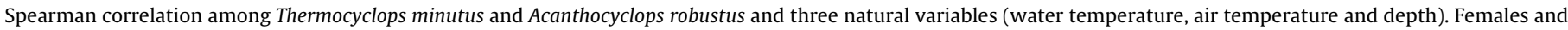
males are identified with (f) and (m), respectively.

\begin{tabular}{|c|c|c|c|c|c|c|}
\hline & T. minutus (f) & T. minutus (m) & A. robustus (f) & Water temperature & Air temperature & Depth \\
\hline T. minutus (f) & 1 & 0.72 & -0.07 & -0.02 & -0.00 & 0.20 \\
\hline T. minutus (m) & & 1 & -0.06 & -0.06 & -0.08 & 0.00 \\
\hline A. robustus $(\mathrm{f})$ & & & 1 & -0.11 & -0.15 & 0.00 \\
\hline Water temperature & & & & 1 & 0.86 & -0.20 \\
\hline Air temperature & & & & & 1 & -0.01 \\
\hline Depth & & & & & & 1 \\
\hline
\end{tabular}

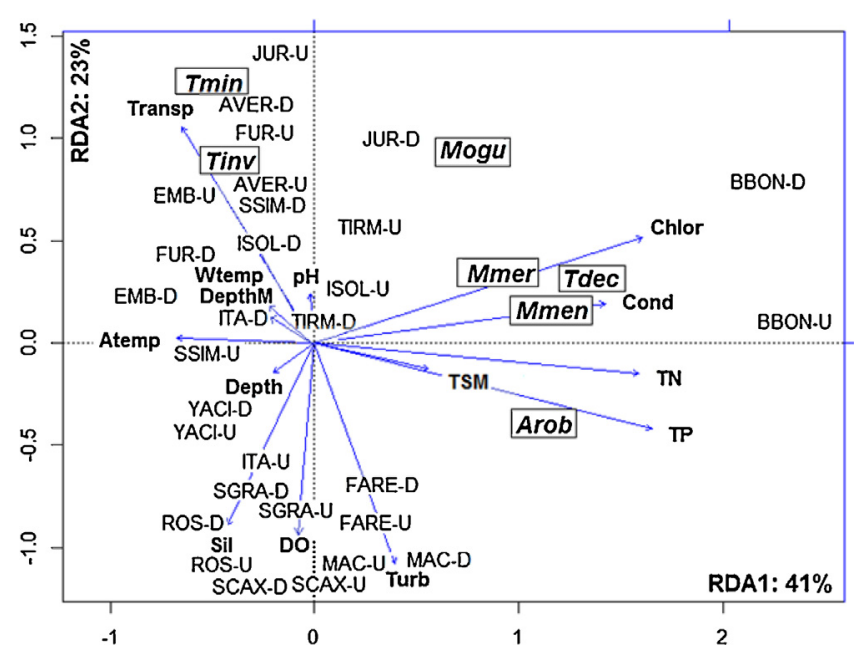

Fig. 3. Biplot of redundancy analyses, between most abundant species of cyclopoid copepods and environmental variables. For codes of species see Fig. 3 legend. Codes of limnological variables: $\mathrm{TN}=$ total nitrogen; $\mathrm{TP}=$ total phosphorus; $\mathrm{TSM}=$ total suspended matter; WTransp = water transparency; Chlor = chlorophyll-a concentration; Cond=electrical conductivity; $\mathrm{DO}=$ dissolved oxygen; WTemp $=$ water temperature; Atemp = air temperature; Turb = turbidity.

plementary file 4). Biplots of coefficient regressions from the first and second axis of PLS are available in Supplementary file 5.

We can highlight that nutrients, chlorophyll, depth, and water transparency have a positive effect on copepod species abundances; in contrast, it is negatively related with total suspended matter. We found positive effects of total phosphorus and chlorophyll-a and negative effects of transparency and total suspended matter for A. robustus. Mesocyclops meridianus was positively correlated to total phosphorus, chlorophyll-a, and depth and negatively to dissolved oxygen, transparency, and total suspended matter. Mesocyclops oggunus were positively related to total phosphorus, chlorophyll-a, and water transparency and negatively to total suspended matter. The M. mendocinus was positively related to total phosphorus and chlorophyll-a and negatively to total suspended matter. Thermocyclops decipiens was positively related to total phosphorus and chlorophyll-a but negatively to total suspended matter.
For the indicators of oligo/mesotrophic conditions, we found $T$. inversus positively related to chlorophyll, water transparency, and total suspended matter and negatively to total phosphorus. Thermocyclops minutus had a positive relation with chlorophyll-a and water transparency and a negative relationship with total phosphorus; however, total suspended matter and mean depth oscillated between positive and negative effects.

\section{Discussion}

The cyclopoid copepod abundance proved to be useful to qualify and monitoring the water quality of reservoirs in a large river basin, as shown by the different statistical analyses employed here. Besides this general trend, only two species were selected by the applied biomonitoring protocol. Thermocyclops minutus and $A$. robustus are very distinct species of copepods with respect to their size and response to chlorophyll-a concentration, total phosphorus, and water transparency, but both were able to contrast eutrophic and oligotrophic reservoirs. Due to this behavior, we recommend the monitoring of these populations as a basic tool to qualify the water quality within the La Plata basin.

One of the most common groups used in biomonitoring are benthic macroinvertebrates, especially aquatic insects (Bonada et al., 2006). One suggested advantage of these groups is the well-described taxonomy and established identification methods that are available (Rosenberg and Resh, 1993). However, this is not true for tropical regions where species level identification is still difficult, and most studies rely on genus level identification (Saito et al., 2015). In contrast with this scenario is the identification of zooplankton where species level is commonly used and several taxonomical and biogeographical studies are being made (Perbiche-Neves et al., 2014). In this sense, the better precision of considering the same species in a large-scale biomonitoring scheme could be an advantage for implementing a zooplankton-based protocol instead of one based on aquatic insects in the La Plata basin. It would avoid confounding responses of congeneric species that respond differently to impacts, a recurrent problem of using higher taxa generalizations (Landeiro et al., 2012).

Thermocyclops minutus has already been identified as being sensitive to eutrophication and has been previously suggested as an indicator of oligotrophic condition in smaller spatial scale studies (Silva and Matsumura-Tundisi, 2005). However, its usefulness

Table 3

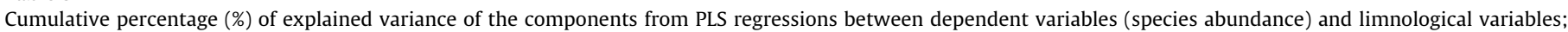
limnological variables associated by the results of all analysis with trophic state indication.

\begin{tabular}{|c|c|c|c|c|c|c|}
\hline & \multicolumn{2}{|c|}{ Dependent variable $(\mathrm{Y})$} & \multicolumn{2}{|c|}{ Limnological variables $(\mathrm{X})$} & \multirow[t]{2}{*}{ Limnological variables associated and values } & \multirow[t]{2}{*}{ Trophic state } \\
\hline & Comp. 1 & Comp. 2 & Comp. 1 & Comp. 2 & & \\
\hline RDA Scores Axis1 & 49.92 & 61.07 & 51.67 & 76.35 & & \\
\hline Acanthocyclops robustus & 43.27 & 59.61 & 50.27 & 73.86 & Total phosphorus Chlorophyll-a & Eutrophic \\
\hline Mesocyclops meridianus & 41.42 & 53.18 & 48.35 & 76.04 & Total phosphorus; Chlorophyll-a & Eutrophic or Mesotrophic \\
\hline Mesocyclops ogunnus & 32.88 & 53.58 & 50.23 & 70.06 & Total phosphorus; Chlorophyll-a & Eutrophic or Mesotrophic \\
\hline Metacyclops mendocinus & 55.60 & 66.70 & 52.11 & 76.36 & Total phosphorus; Chlorophyll-a & Eutrophic \\
\hline Thermocyclops decipiens & 27.88 & 38.40 & 44.33 & 75.97 & Total phosphorus; Chlorophyll-a & Eutrophic \\
\hline Thermocyclops inversus & 17.39 & 31.54 & 52.20 & 69.73 & Water transparency & Mesotrophic/Oligotrophic \\
\hline Thermocyclops minutus & 28.45 & 60.99 & 51.51 & 64.14 & Water transparency & Oligotrophic \\
\hline
\end{tabular}


for large scale assessment was unclear. Here, supporting these previous findings, we corroborate that Thermocyclops minutus, an endemic but widespread species of South America (Bonecker et al., 2001), is a suitable indicator of oligotrophic conditions for the La Plata basin. In contrast, we found that $A$. robustus was more prone to detect eutrophication than $T$. decipiens, which is a commonly suggested bioindicator (Landa et al., 2007). Thermocyclops decipiens was suggested as suitable for monitoring a small area in Brazil (Landa et al., 2007), but we found that this species did not respond in the same way for the entire La Plata basin, thus demonstrating the importance of spatial scale when selecting biomonitoring species. Moreover, A. robustus was found to not be successful in eutrophic lakes in different regions of the world (Maier, 1998), but it was the best indicator of eutrophication for the La Plata basin. A possible explanation is that different regions have different competitors and predators of $A$. robustus that likely influence its abundance differently, reflecting its ability to detect eutrophication in different regions.

Acanthocylops robustus along with other species (e.g., M. mendocinus, T. decipiens, M. meridianus, and $M$. ogunnus) were abundant in the Barra Bonita Reservoir (Tietê River, São Paulo, Brazil), which is probably the most polluted reservoir in the entire basin, which receives sewage from São Paulo city (containing more than 20.000.000 habitants). These species were related to the total phosphorus and nitrogen, chlorophyll-a, and conductivity, which are typical variables of eutrophic environments (MatsumuraTundisi and Tundisi, 2005; Santos-Wisniewski and Rocha, 2007). A mechanistic explanation for their abundance is that eutrophic conditions favor some zooplankton species that produce large populations supported by huge phytoplankton biomass. Dominant cyclopoid copepods can win the competition for resources with other microcrustaceans due to high toleration to disturbed conditions (Santos-Wisniewsky and Rocha, 2007), as low dissolved oxygen, algae toxins, and a game of pollutants. However, dominant species in eutrophic/hypereutrophic environments generally show irregular variation along space and time (Perbiche-Neves et al., 2007; Nishimura et al., 2014) without predictability or stability of dominant species in each year in a sequence, suggesting that further studies should investigate whether $A$. robustus is the best indicator of eutrophication through time, or if it should be used in combination with other species that also benefit from eutrophication.

The results of this study confirm the use of Thermocyclops minutus as an indicator of oligotrophic condition (Landa et al., 2007; Silva, 2011) and along with T. inversus and T. minutus were favored in oligotrophic/mesotrophic reservoirs associated with water transparency. A likely explanation is that these small-bodied species are favored in reservoirs with higher water transparency because they are less visible to predators. Conversely, larger species that can be common in eutrophic reservoirs would be more exposed to predators, as supported by the negative relationship found between $A$. robustus and water transparency. The quantity of algae (measured by chlorophyll-a concentration) is another barrier to support high populations of larger copepod species, due to a combination of bottom-up and top-down effects. So, large species of copepods are probably not abundant in oligo/mesotrophic reservoirs because they require large amounts of algae and also because of predation. A trend of body size and dominance can be investigated in the future, since large species of cyclopoids likely dominate eutrophic reservoirs with high water transparency and small cyclopoids dominate in oligo/mesotrophic reservoirs.

\section{Conclusion}

The large distribution of copepods species in the La Plata basin is a potential advantage to use this group as a large-scale bioindica- tor. Species that respond predictably to impacts but with restricted distribution are not useful tools for monitoring since regional modifications must occur to adapt the monitoring (Bonada et al., 2006). In this sense, the predictable response of widespread copepods species is an important finding of this study.

Large-scale assessments that encompass more than one country and different ecoregions are already being implemented in Europe and North America but not in South America and in less developed regions. In this way, we provided initial evidence for effective biomonitoring and suggest that future biomonitoring studies encompassing the entire La Plata basin focus on Thermocyclops and Acanthocyclops species.

\section{Acknowledgements}

To FAPESP for financial support (process number 2008/020157; 2009/00014-6; 2011/18358-3); and to J.R. Debastiani Jr., D.A.O. Naliato, J.L. Portinho, and S. Casanova for help in fieldwork.

\section{Appendix A. Supplementary data}

Supplementary data associated with this article can be found, in the online version, at http://dx.doi.org/10.1016/j.ecolind.2016. 06.028.

\section{References}

Barbosa, F.A.R., Padisak, J., Espíndola, E.L.G., Borics, G., Rocha, O., 1999. Ecological theory applied to reservoir zooplankton. In: Tundisi, J.G., Straskraba, M. (Eds.), Theoretical Reservoir Ecology and Its Applications. Brazilian Academy of Sciences, International Institute of Ecology and Backhuys Publishers, Leiden, pp. 457-476.

Barbour, M.T., Gerritsen, J., Griffith, G.E., Frydenbourg, R., Mccarron, E., White, J.S., Bastian, M.L., 1996. A framework for biological criteria for Florida streams using benthic macroinvertebrates. J. N. Am. Benthol. Soc. 15, 185-211.

Bonada, N., Prat, N., Resh, V.H., Statzner, B., 2006. Developments in aquatic insect biomonitoring: a comparative analysis of recent approaches. Annu. Rev. Entomol. 51, 495-523.

Bonecker, C.C., Lansac-Tôha, F.A., Velho, L.F.M., Rossa, D.C., 2001. The temporal distribution patterns of copepods in Corumbá Reservoir, State of Goiás, Brazil. Hydrobiologia 453/454, 375-384.

Burger, J., 2007. A framework and methods for incorporating gender-related issues in wildlife risk assessment: gender-related differences in metal levels and other contaminants as a case study. Environ. Res. 104, 153-162.

Carlson, R.E., 1977. A trophic state index for lakes. Limnol. Oceanogr. 22, 361-380.

Clarke, K.R., 1993. Non-parametric multivariate analyses of changes in community structure. Aust. J. Ecol. 18, 117-143.

Dodds, W.K., Bouska, W.W., Eitzmann, J.L., Pilger, T.J., Pitts, K.L., Riley, A.J., Schloesser, J.T., Thornbrugh, D.J., 2008. Eutrophication of U.S. freshwaters: analysis of potential economic damages. Environ. Sci. Technol. 43 (1), 12-19.

Hering, D., Feld, C.K., Moog, O., Ofenböck, T., 2006. Cook book for the development of a multimetric index for biological condition of aquatic ecosystems: experiences from the European AQEM and STAR projects and related initiatives. Hydrobiologia 566, 311-324.

Landa, G.G., Barbosa, F.A.R., Rietzler, A.C., Barbosa, P.M., 2007. Thermocyclops decipiens (Kiefer, 1929) (Copepoda, Cyclopoida) as indicator of water quality in the state of Minas Gerais, Brazil. Braz. Arch. Biol. Technol. 50 (4), 695-705.

Landeiro, V.L., Bini, L.M., Costa, F.R.C., Franklin, E., Nogueira, A., Souza, J.L.P. Moraes, J., Magnusson, W.E., 2012. How far can we go in simplifying biomonitoring assessments? An integrated analysis of taxonomic surrogacy, taxonomic sufficiency and numerical resolution in a megadiverse region. Ecol. Indic. 23, 366-373.

Maier, G., 1998. Differential success of cyclopoid copepods in the pelagic zone of eutrophic lakes. J. Mar. Syst. 15, 1-4 (135-138).

Matsumura-Tundisi, T., Tundisi, J.G., 2003. Calanoida (Copepoda) species composition changes in the reservoirs of São Paulo State (Brazil) in the last twenty years. Hydrobiologia 504, 215-222.

Matsumura-Tundisi, T., Tundisi, J.G., 2005. Plankton richness in a eutrophic reservoir (Barra Bonita Reservoir, SP, Brazil). Hydrobiologia 542, 367-378.

Mevik, B.H., Wehrens, R., 2007. The pls package: principal component and partial least squares regression in R. J. Stat. Softw. 18 (2), 1-24.

Mevik, B.H., Wehrens, R., Liland, K.H., 2013. pls: Partial Least Squares and Principal Component Regression. R Package Version 2.4-3 [online document]. URL http://CRAN.R-project.org/package=pls (accessed 27.12.14).

Neves, G.P., 2011. Planktonic Copepods (crustacea, Calanoida and Cyclopoida) in Reservoirs and Lotic Stretches in the Basin of de La Plata River (brazil, Paraguay, Argentina and Uruguay): Taxonomy, Geographical Distribution and Some Ecological Attributes. Doctorate Thesis (in Portuguese). Universidade 
Estadual Paulista, Botucatu, São Paulo State, Brazil, Available at: http://www. ibb.unesp.br/posgrad/teses/zoologia_do_2011_gilmar_neves.pdf 235p (accessed in 08.03.16).

Nishimura, P.Y., Meirinho, P.A., Moschini-Carlos, V., Pompêo, M.L.M., 2014. Does the plankton community follow the horizontal water quality heterogeneity in a tropical urban reservoir (Guarapiranga reservoir, Sêo Paulo, Brazil)? Limnetica 33 (2), 263-280.

Nogueira, M.G., Reis-Oliveira, P.C., Britto, Y.T., 2008. Zooplankton assemblages (Copepoda and Cladocera) in a cascade of reservoirs of a large tropical river (SE Brazil). Limnetica 27 (1), 151-170.

Oksanen, J., Blanchet, F.G., Kindt, R., Legendre, P., Minchin, P.R., O’Hara, R.B. Simpson, G.L., Solymos, P., Henry, M., Stevens, H., Wagner, H., 2014. Vegan: Community Ecology Package. R Package Version 2. 2-0 [online document]. URL http://CRAN.R-project.org/package=vegan (accessed 27.12.14).

Perbiche-Neves, G., Serafim-Júnior, M., Ghidini, A.R., Brito, L., 2007. Spatial and temporal distribution of Copepoda (Cyclopoida and Calanoida) of an eutrophic reservoir in the basin of upper Iguaçu River, Paraná, Brazil. Acta Limnol. Bras. 19 (4), 393-406.

Perbiche-Neves, G., Boxshall, G.A., Nogueira, M.G., Rocha, C.E.F., 2014. Trends in copepod diversity in reservoirs and lotic stretches in a large river basin in South America. Mar. Freshw. Res. 65 (8), 727-737, http://dx.doi.org/10.1071/ MF13109.

R Development Core Team, 2016. A Language and Environment for Statistical Computing. R Foundation for Statistical Computing, Vienna, Austria, ISBN
3-900051-07-0, Available online at: http://www.R-project.org (accessed 09.06.16).

Rietzler, A.C., Matsumura-Tundisi, T., Tundisi, J.G., 2002. Life cycle, feeding and adaptive strategy implications on the co-occurence of Argyrodiaptomus furcatus and Notodiaptomus iheringi in Lobo-Broa Reservoir (SP, Brazil). Braz. J. Biol. 62, 93-105

Rosenberg, D.M., Resh, V.H., 1993. Introduction to Freshwater Biomonitoring and Benthic Macroinvertebrates. Chapman and Hall, New York.

Saito, V.S., Siqueira, T., Fonseca-Gessner, A.A., 2015. Should phylogenetic and functional diversity metrics compose macroinvertebrate multimetric indices for stream biomonitoring? Hydrobiologia 745, 167-179.

Santos-Wisniewsky, M.J., Rocha, O., 2007. Spatial distribution and secondary production of Copepoda in a tropical reservoir. Braz. J. Biol. 67 (2), 223-233.

Serafim-Júnior, M., Perbiche-Neves, G., Brito, L., Ghidini, A.R., Casanova, S.M.C. 2010. Spatial-temporal variation of Rotifera in an eutrophic reservoir in southern Brazil. Iheringia 100 (3), 233-241.

Silva, W.M., Matsumura-Tundisi, T., 2005. Taxonomy, ecology, and geographical distribution of the species of the genus Thermocyclops Kiefer, 1927 (Copepoda, Cyclopoida) in São Paulo State, Brazil, with description of a new species. Braz. J. Biol. 65 (3), 521-531.

Silva, C.A., Train, S., Rodrigues, L., 2005. Phytoplankton assemblages in a Brazilian subtropical cascading reservoir system. Hydrobiologia 537, 99-109.

Silva, W.M., 2011. Potential use of Cyclopoida (Crustacea, Copepoda) as trophic state indicators in tropical reservoirs. Oecol. Aust. 15 (3), 511-521. 